\title{
Did Kettlewell commit fraud? Re-examining the evidence
}

\author{
David Wÿss Rudge
}

H.B.D. Kettlewell is famous for several investigations conducted in the early 1950 s on the phenomenon of industrial melanism, which are widely regarded as the classic demonstration of natural selection. In a recent (2002) booklength popularization of this episode in the history of the science, science writer Judith Hooper draws attention to what she interprets as discrepancies in the results reported by Kettlewell in his first scientific papers on the subject. On the basis of correspondence among Kettlewell and his associates, a survey of scientific publications that mention outstanding questions surrounding the phenomenon, as well as interviews with his son, surviving colleagues, and scientists who have worked on industrial melanism, Hooper all but explicitly concludes that Kettlewell committed fraud. The following essay critically examines her evidence in support of this allegation, including her discussion of his character, the alleged motives, and whether fraud was even committed. None of Hooper's arguments is found to withstand careful scrutiny. The concluding section draws several conclusions about how history of science should be depicted to the public.

\section{Introduction}

Bernard (H.B.D.) Kettlewell is famous for several investigations he conducted in the early 1950s on the phenomenon of industrial melanism, the rapid rise in frequency of dark forms of many moth species in the vicinity of manufacturing centers shortly after the industrial revolution, as an apparent consequence of the first large-scale air pollution. It was first discovered in the peppered moth, Biston betularia, and is now thought to have occurred in at least 100 other species in Britain alone (Kettlewell, 1973; Majerus, 1998).

Kettlewell is widely regarded as the first researcher to establish that dark forms became more common in these areas owing to differential predation by birds. He pointed out that in forests downwind of manufacturing centers, air pollution darkened the resting sites of moths by killing off the normal pale lichen cover and blanketing trees with soot. In such a sootdarkened environment, predators that search for the moths primarily by relying on visual clues would have considerable difficulty spotting dark moths, but would presumably have no such difficulty locating pale moths, which are quite conspicuous against soot-darkened backgrounds. The goal of his first experiment in 1953 was to establish that birds prey upon 
the moth and further that they have the same difficulty spotting dark moths when they rest on soot-darkened tree trunks humans do (Kettlewell, 1955b). The investigation proceeded in three steps. First, Kettlewell developed a procedure to gauge how conspicuous the two forms of the moth are when they rest on pale lichen-covered and soot-darkened backgrounds. Second, he conducted a preliminary experiment using captive birds to determine whether birds eat moths at all, and, if so, whether predation results in a relatively greater loss of the more conspicuous form. Third, in his most celebrated experiments, he released marked examples of pale and dark moths into a polluted setting and attempted to recapture as many as possible using a combination of mercury vapor light and assembling traps. The logic behind this experiment was that if a higher recapture rate for one form was found, it was evidence that the form was at an advantage in that environment. Kettlewell found that, in the polluted environment, the recapture rate of the dark form was twice as high as that for the light form. By ruling out other possible explanations, as well as by directly observing birds eating moths in the manner predicted, he concluded that the dark forms were at a selective advantage in the polluted environment, owing to differential predation by birds. A companion experiment conducted in 1955 in an unpolluted environment demonstrated the reverse (Kettlewell, 1956). In unpolluted woods, the lichen cover associated with trees constitutes a pale background against which the pale form of the moth is difficult to distinguish, but the dark forms are much easier to spot. Using a similar mark-releaserecapture experiment, Kettlewell documented that, in this environment, the recapture rate for the pale form was higher. Kettlewell is widely regarded as having clinched the case that this difference in recapture rate was due to differential predation by having an associate, Niko Tinbergen, film the more conspicuous form of the moth being preyed upon first by birds in both settings.

As one might imagine, the actual story of Kettlewell's work on industrial melanism is more complicated than the above paragraph suggests. Over the past 50 years, researchers on the phenomenon have drawn attention to three fundamental problems in the way Kettlewell's initial studies were conducted and interpreted, which are summarized in Majerus (1998). First, Kettlewell chose to introduce large numbers of moths in excess of the endemic population so as to ensure that the results would be statistically significant, which raises the possibility that his results were simply an artifact of the elevated densities of moths used. Second, Kettlewell released moths on the assumption that they spend most of the day in plain sight on the trunks of trees; however, in fact, the actual resting location is not well known and there is some evidence that they may rest higher up in the canopy. Third, Kettlewell's investigations apparently relied on a combination of both laboratory-bred and "wild caught" insects, which opens up the possibility that differences in the recapture rate might reflect differences in survivorship between these two variants. Despite these problems, review articles have repeatedly drawn attention to the fact that multiple investigations by subsequent researchers support the basic outlines of Kettlewell's explanation (Berry, 1990; Grant, 1999; Cook, 2000, 2003). Perhaps the most striking line of evidence in its favor, however, has been studies since the advent of Clean Air Legislation in both Britain and the United States that document that the predicted decline of the dark form has indeed occurred (Grant et al., 1996). While several problems still remain (as is the case in any active area of scientific investigation), among virtually all scientists who work on the phenomenon there is no question that industrial melanism is an example of natural selection and that bird predation is the major-but not the only-selective factor at work (Grant, 1999; Cook, 2003).

It is striking that, despite our current scientific understanding that the phenomenon is more complex than initially recognized by Kettlewell, industrial melanism has had a very 
different fate among the lay public and the popular press. Since the early 1960s, it became the example of choice for illustrating natural selection both in textbooks and in the popular media. Part of its ubiquity rests in several pedagogic advantages associated with this particular example, including the relative simplicity of the phenomenon, the familiarity most introductory students can be expected to have with its major elements (birds, moths, pollution and predation), and its conduciveness to visual representation (Rudge, 2000, 2003). At least part of its fame lies in the adroit way that Kettlewell and other members of the group he worked with at Oxford publicized this particular example in order to promote the teaching of evolution and to secure funding for their research endeavors.

Consideration of these other factors suggests there might be another heretofore-untold story surrounding Kettlewell's work. In a recent popularization of this episode in the history of science, science writer Judith Hooper uncovers what she regards as a series of mysteries surrounding both the phenomenon of industrial melanism and Kettlewell's work upon it (Hooper, 2002). Her analysis draws great attention to: (1) the fact that summaries of the phenomenon grossly oversimplify a complex episode in science; (2) the existence of outstanding questions and interpretive problems associated with nearly every aspect of the phenomenon; and, in particular, (3) an apparent discrepancy in the results Kettlewell reported in his 1955 and 1956 papers. On the basis of these considerations, Hooper raises the possibility that Kettlewell committed fraud and that his colleagues at Oxford-most notably E.B. (Henry) Ford-were complicit (at least to the extent that they actively tried to suppress evidence that might have led people to question the standard account). A careful review of Hooper's arguments demonstrates that they rest upon an obvious agenda, poor historical scholarship, mistakes in scientific reasoning, and several fundamental misunderstandings about the nature of science and evolutionary biology.

\section{Critique of Hooper's "argument"}

Fraud in the context of science refers to the misrepresentation of data. It ranges from the deliberate manufacturing of data and/or altering of experimental results to the fudging of data and only reporting good results (Martin, 1992). While socially defined, and therefore subject to change, it is not a charge that should be bandied about lightly in the context of popularizations, particularly in the absence of careful research to substantiate that fraud has indeed occurred. As Hooper herself recognizes, allegations of fraud are among the most serious in science. ${ }^{2}$

While Hooper does not explicitly charge Kettlewell with fraud, there can be no doubt that this is the intended interpretation she wishes the reader to draw from her book, as she writes:

When the Nobelist Sir Peter Medawar famously declared: "The scientific paper is a fraud," he was referring to the fact that science doesn't always proceed according to Popper's ideal of the hypothetico-deductive method, but he may also have been thinking of human factors (ambition, jealousy, rush to publication, megalomania, behind the scenes maneuverings, even sex, illness and desperation) that are sanitized out of journals. Underlying the traditional science paper - as Karl Sabbagh observes in $A$ Rum Affair, the tale of Heslop-Harrison - "are several layers of unreported facts - facts that could never be reported without legal advice - about U's incompetence, V's marriage break-up, W's burning desire to win a Nobel prize, X's dislike of experiment, Y's irrational belief in a particular theory against all evidence, Z's need to please his or her boss." "We could fill in the blanks: Bernard's desperate need to please E. B. Ford, 
Ford's fanatical belief in the power of adaptation, everybody's craving for merit badges (an FRS for Bernard, a knighthood for Henry perhaps). Then there were Bernard's family problems, his insecure finances, his craving for recognition at Oxford, the "turns" he suffered during his experiment, his exhaustion, sleep deprivation and mood swings, even the emotional aridity of his childhood. We might add Henry's desire for revenge on his enemies, his idolatry of Sir Ronald Fisher, the intrigues and turf wars within the zoology department at Oxford, his investment in his experiments with Maniola jurtina and Panaxia, his grandiosity, even his discomfort with females. Traditionally, these human factors are deemed irrelevant to the scientific process, as if scientists were a race of hard-wired robots. (Hooper, 2002: 298-9) ${ }^{4}$

The "argument" Hooper provides for this charge, alluded to in the above paragraph, extends throughout her entire book. Her approach constitutes a three-pronged attack, aimed at establishing (1) that Kettlewell was of such a character that he was indeed capable of committing fraud, (2) that he had a pressing motive to do so, and further (3) that an apparent discrepancy in results presented in his published reports is evidence that Kettlewell "fudged" his data. In the following subsections, I will evaluate her arguments for each of these claims.

\section{A question of character}

Much of Hooper's book is devoted to sharing a series of mostly previously published stories about the colorful members of what has come to be known as Ford's "Oxford School of Ecological Genetics" (cf. Turner, 1985). ${ }^{5}$ One can hardly fault her in the context of a biography for sharing some of the details of their personal lives, as this is necessary to humanize the story and to clarify some of the interactions among her protagonists. However, given the enormous amount of space devoted to this end, one cannot help but wonder whether the extended discussions of the personalities, characters and private lives of the protagonists are intended as evidence for the serious charges Hooper has leveled against them. The answer is resoundingly clear from the following passage:

The roots of the peppered moth story lie deep in the personal histories of a small number of scientists, preserved in the memories of friends, colleagues and family, as well as in letters bound in satin ribbons at the New Bodleian Library at Oxford. At the very moment that the peppered moth experiments were establishing the Oxford biologists as masters of their world, their personal and professional relationships were disintegrating in a miasma of recriminations, intrigue, jealousy, back-stabbing, and shattered dreams. They conceived the evidence that would carry the vital intellectual argument, but at its core lay flawed science, dubious methodology, and wishful thinking. Clustered around the peppered moth is a swarm of human ambitions and selfdelusions, shared among some of the most renowned evolutionary biologists of our era. (Hooper 2002: xix-Xx)

Nearly half of Hooper's book is devoted to establishing that Kettlewell, Ford, and others associated with work on the peppered moth were of such a character that they would commit fraud and conspire to hide the details. ${ }^{6}$

It is striking, in light of how much space is devoted to this end, that, for many of the personal details Hooper chooses to discuss at length, the connection to the charges of fraud and conspiracy are never explicitly made. For instance, Hooper draws great attention to the fact that Ford had a reputation as a misogynist (pp. 54, 56, 58-61, 229-30). It is certainly plausible that this might have affected the conduct of research at Oxford. However, all of the 
principal scientists in this story are men. The one prominent female scientist associated with this group, Dr. Miriam Rothschild, found Ford to be "exceedingly kind and understanding" (Clarke, 1995: 152). Hooper even admits that he was "typically gracious," "courtly" and "grateful" towards his secretaries (p. 101). While it is true that he was at times incredibly rude to female students and the wives of graduate students, it is fairly clear he was rude on occasion to everyone (Clarke, 1995: 153). Yet, what, if anything, does the fact a person is a misogynist (or more accurately, has a reputation as a misogynist) have to do with whether that person would commit fraud and/or conspiracy? Similarly, one can question Hooper's decision to discuss many details of Kettlewell's private life, including his reputation as a philanderer, the sordid details surrounding his daughter's death, and his apparent suicide. If Hooper sincerely believes these details are evidence that Ford and Kettlewell would commit fraud or conspiracy, it is simply an argument ad hominem. If, however, in contrast to what the lengthy quotation above implies, they are not intended as evidence in favor of the book's theses, it is hard not to interpret her decision to discuss these details at length as simply an inflammatory attempt to titillate the reader.

That being said, there are some details Hooper chooses to share about Kettlewell's professional life that are relevant to her contention that he was capable of committing fraud. Hooper draws attention to Kettlewell's background choice experiments and his investigations into the build-up of dominance in the peppered moth. In both cases, it is clear that strong theoretical convictions may have led Kettlewell astray when it came to interpreting the results of these investigations (Majerus, 1998). Hooper's strategy in drawing attention to these examples is obvious - if he committed fraud in these two cases, is it not plausible that he committed fraud during his more famous predation experiments on the phenomenon of industrial melanism?

There are two problems with this line of reasoning. First, being wrong is not, in and of itself, evidence that one has committed fraud. If the history of science has demonstrated anything, it is that the eventual fate of all scientific theories is to be proven wrong. We do not fault Darwin as a scientist for advancing a theory of inheritance (his theory of pangenesis) simply because it was ultimately discredited. Second, it is mistaken to discredit scientists for having convictions and sticking with them. It is, for instance, precisely because Watson and Crick were convinced that the genetic code must be simple and elegant that they persisted-despite several false starts—and ultimately determined the structure of DNA. It may at times be difficult to distinguish between strong intuitions about processes that have a basis in the world of experience from those that do not; hence the importance in science of repeatability by other scientists. In the case of Kettlewell's work on background choice and his theory of the build-up of dominance, it was the inability of others to repeat his results that ultimately discredited these two lines of investigation. With regard to the predation experiments on industrial melanism, in contrast, numerous studies have qualitatively confirmed the results of Kettlewell's investigations (Berry, 1990; Cook, 2003).

Yet another line of evidence Hooper uses to establish that Kettlewell was capable of committing fraud is to cast doubt on his abilities as a scientist. To establish this, Hooper describes Kettlewell as "not a research scientist by training but a medical doctor" (p. xvi) and repeatedly refers to him as an "amateur" (pp. xvi, 123, 159). While admitting his remarkable skills as a naturalist, she also repeatedly denigrates his abilities as a scientist: "Bernard was an extraordinarily gifted lepidopterist who was weak in genetics, statistics and evolutionary theory" (p. 212). This characterization is decidedly unfair, if not misleading. Ford regarded Kettlewell as "the finest living ecologist of the Lepidoptera" (Ford, 1979), and R.J. Berry referred to him as "the best naturalist I have ever known" (Berry, 1990), both of which contrast with Hooper's tacit suggestion that the work he did was inferior because 
of his lack of professional training. Indeed, it was the extensive connections with over 150 amateur entomologists - which Kettlewell had cultivated for decades prior to his association with Ford-that enabled him to conduct the extensive surveys of the distribution of melanic forms throughout Britain, and that, in turn, were the basis for the whole betularia study. Professional academics typically do not have the time, experience or resources for travel and collecting that such an undertaking would involve. Describing Kettlewell as "weak in genetics" is also particularly misleading-it completely ignores the informal training he received over a period of at least twenty years under the tutelage of E.A. Cockayne, who, among other things, was nominated to serve as President of the Genetical Society by J.B.S. Haldane and seconded by Cyril Darlington. ${ }^{7}$ As a result of this collaboration, Kettlewell published the results of several breeding and temperature experiments.

Hooper also draws great attention to published remarks by Sam (R.J.) Berry, a junior associate, who referred to Kettlewell as "the worst professional scientist I have ever known" and added that "[w]riting papers with him was traumatic; as an experienced clinician he made rapid diagnoses and refused to be diverted by what he regarded as irrelevant evidence" (Berry, 1990: 322). One must be very careful in evaluating such a comment. ${ }^{8}$ First, while being disorganized, dogmatic and having difficulty writing papers are all indications that one may not be the best of scientists, these comments alone are not evidence that such an individual would commit fraud. Second, the reminiscences upon which Hooper bases her account are primarily by those who knew Kettlewell during the last years of his life, and they may therefore be misleading when it comes to understanding him and his motivations at the time of the investigations. His life-long friend Eric Classey, while freely admitting Kettlewell was not the most careful of scientists, completely denies that he was capable of committing fraud, a perspective consistently maintained by all of the scientists who worked with him. ${ }^{9}$

As a third line of evidence, Hooper resorts to the fact that Kettlewell was exhausted and suffering from a variety of physical and psychological ailments at the time of his investigations, as if this is evidence that his condition might somehow prompt him to commit fraud and act out of character (pp. 70, 88-9, 112, 133, 180-2, 193, 206, 223-5). Recognition of the difficult conditions he worked under at the time can just as easily be interpreted as an indication of heroic dedication and self-sacrifice in the name of science. Do we seriously question the merits of physicist Stephen Hawking's work upon learning that he has ALS (amyotrophic lateral sclerosis) or the merits of John Nash's work when we discover that this Nobel Laureate mathematician was diagnosed as a paranoid schizophrenic? Merely being ill, tired or insecure is not sufficient evidence that one would be willing to commit fraud.

\section{What was Kettlewell's alleged motive?}

Casting to one side concerns about whether it has indeed been established that Kettlewell was of such a character that he would commit fraud, what possible motives does Hooper suggest might have led Kettlewell to "fudge" his data? Hooper identifies two motives in particular. First, his dogmatic allegiance to a broader pan-selectionist agenda set out by Ford and his colleagues, an agenda whose fate rested upon the success of the investigations. And, second, related to the former, a host of personal insecurities that Kettlewell, a former medical practitioner, had in establishing himself professionally as a researcher at Oxford.

\section{The importance of industrial melanism to the Oxford school of ecological genetics}

In the preface to her book, Hooper sets the stage for her analysis of the motives of Ford and 
his associates by first drawing attention to the "shaky ground" on which Darwin's theory of natural selection rested during the first half of the twentieth century (p. xv). There are multiple reasons that lay behind the "eclipse of Darwinism" during this period, including the advent of numerous alternative mechanisms of evolution (Lamarckian inheritance, orthogenesis) and the rediscovery of Mendelian genetics, which was initially seen as an alternative to Darwin's theory of natural selection (Bowler, 2003: chapter 7). Hooper rejects this standard analysis in favor of a single cause, namely the absence of an experimental demonstration of natural selection "apart from admittedly artificial laboratory studies of fruit flies" (p. xv), and further on she adds that "[t]here was doubt that natural selection could ever be experimentally demonstrated at all, and if it could not, then evolutionary biology was doomed to be a second rate 'historical science,' incapable of being proved or disproved" (pp. $\mathrm{xv}-\mathrm{xvi}$ ). Hence the importance of the phenomenon of industrial melanism, and, in particular, Kettlewell's experimental demonstration.

The problem with this analysis is three-fold. First, Kettlewell's investigations took place well after the period of time that historians of biology refer to as the "evolutionary synthesis" during the 1920 s to 1940 s, when evolutionary biologists are widely seen to have reached consensus on many issues in biology, including the important role of natural selection (Mayr and Provine, 1980). While Haldane's (1924) calculation of the speed of the spread of the carbonaria gene responsible for dark coloration in the peppered moth certainly contributed to this movement in biology, it is misleading to suggest that Kettlewell's experiments played an important role. At most, Hooper can draw attention to the importance of Kettlewell's experiments in testing what was recognized to be a particularly striking example of natural selection, and their subsequent role in what Stephen Jay Gould has dubbed the "hardening of the synthesis" (Gould, 1983). Second, at the time of Kettlewell's studies in the early 1950s, there were already many experimental demonstrations of natural selection, including field experiments (see Dobzhansky, 1951). Third, and perhaps most alarming, is a fundamental misunderstanding about how claims are established in historical sciences like evolutionary biology. Evolutionary biology is a historical science, because many of the phenomena in its domain are historical, and, indeed, take place on a geologic time scale. The extended nature of evolutionary phenomena in time often precludes experiments that can be conducted within the span of human lifetimes.

Contrary to what Hooper (2002: 163-4) suggests, the foregoing does not imply that "anything goes" when it comes to claims in evolutionary biology, just as the fact that there are no eyewitnesses does not preclude a crime scene investigator from reaching reliable conclusions about the past. Like detectives, evolutionary biologists not only infer what might have led to the patterns they observe, but they also trace implications of these inferences that can be the object of independent tests (e.g. experiments and observations). There are some evolutionary phenomena that can be tracked and studied in the span of a human lifetime, which are referred to as microevolutionary phenomena. The fact that microevolutionary processes can be studied experimentally while macroevolutionary processes cannot does not imply that claims about macroevolutionary phenomena are merely speculations about the long-term consequences of phenomena that can be studied experimentally. Nor does it lead to the conclusion that, in the absence of experimental evidence, there is no reliable basis upon which claims about macroevolution can be tested and supported. Darwin's theory of common descent won the scientists of his day over in a relatively short period of time, not because of dramatic experimental demonstrations, but rather because of the explanatory power of his theory, its ability to unite otherwise disparate phenomena, and its fruitfulness in opening up new areas of investigation (Kitcher, 1985). 
Many of Darwin's claims about the history of life were eminently testable by means of comparative observations.

Beyond all this, the slur mentioned above against the historical sciences reflects a deepseated misunderstanding about what it means to "prove" something in science. The suggestion that "proof" in science only occurs in the context of experimental investigations, i.e., only when we directly observe it under controlled circumstances, is completely misguided for two reasons. First, experiments do not establish claims with the certitude that Hooper and others appear to suggest. Just as historical claims are always subject to the possibility that new evidence and/or new ways of interpreting data may lead investigators to change their interpretation, so too are the results of experiments, as Hooper's own review of the literature surrounding Kettlewell's investigations amply documents. Scientific knowledge is always tentative, regardless of the method used. Second, even claims made by highenergy physicists on the basis of the most rigorous of experiments are interpreted as holding true for similar situations in both time and space. In other words, not only is there an inductive step associated with the interpretation of experiments, but there is also an inductive step associated with the extension of results to other situations. Viewed in this way, the fact that scientists make claims about the past that can never (short of by using a time machine) be verified by direct observation, is no different in kind than the inductive step we associate with extending the results of an experiment on the motion of masses on the earth to claims about what happens to masses on planets in other galaxies.

Hooper continues: "Fighting against a sea of Lamarckians, saltationists, macromutationists, and 'random drift' believers, a resolute band of neo-Darwinians sought the perfect example to prove their case" (p. xvi). This claim is completely mistaken with reference to Kettlewell's work on the phenomenon of industrial melanism. Saltationism and macromutation are theories of macroevolution, so the phenomenon of industrial melanism was not even relevant to these debates. Nor did the peppered moth figure prominently in debates about random drift. Indeed, it is unclear that random drift was ever seriously considered as an explanation for the phenomenon of industrial melanism. ${ }^{10}$ Nor (contra Hooper, 2002: 91-6) did it figure prominently in Ford's ongoing debates with Wright, because their published correspondence does not even mention it. Ford's Ecological Genetics' extensive discussion of drift does not address industrial melanism at all, nor does the chapter he devotes to melanism refer to drift (Ford, 1975). The placement of the chapter devoted to "Transient Polymorphism and Melanism" is also significant. Far from occupying the prominent position that Hooper would have us believe, it is buried as the fourteenth of fifteen chapters at the end of the book. Chapter one, which is devoted to defining the scope and aims of ecological genetics with multiple examples, does not even touch on industrial melanism.

Even with reference to Lamarckianism, a theory that was used to explain industrial melanism by J.W. Heslop-Harrison (1927), it is far from clear that Kettlewell's experimental demonstration that the phenomenon could be accounted for by natural selection was indeed the definitive blow to this theory. Hooper's sympathetic treatment of Theodore Sargent's interpretation of industrial melanism aside, Lamarckian inheritance is generally regarded as having been discredited because of the implausibility of its mechanism. Once again, part of the problem with Hooper's interpretation rests on a fundamental misunderstanding, this time about debates in evolutionary biology. The debates she mentions were not an all-or-nothing affair, but rather debates about the relative importance of these mechanisms (Beatty, 1995). No one seriously doubted that some evolutionary phenomena, particularly adaptations, might be accounted for by natural selection-least of all Sewall Wright (Provine, 1986).

Like so many creationist and intelligent-design theorists who have written about this 
episode before her (e.g. Wells, 2000), Hooper takes the ubiquity of the phenomenon of industrial melanism in biology textbooks as evidence of its central importance to evolutionary biology (pp. 146-8, 212, 241-2). The fact that the phenomenon has achieved this status in textbooks owing to the special pedagogic advantages of this example (in particular its conduciveness to visual depiction) seems to have been completely lost on these writers (Rudge, 2000, 2003). Related to this is a fundamental lack of appreciation that for reasons such as limitations of space and their intended audiences, introductory textbook accounts written for children will not (and should not) share the complexities of this episode in the manner one finds in academic journal articles (Rudge, 2002). Textbooks, by their nature, can easily be interpreted as implying that facts found within them are known with much more certitude than is actually the case. Adult commentators such as Hooper and Wells who write about science should know better. There is a story behind every fact in science, and the phenomenon of industrial melanism is hardly unique in this regard.

The simple fact of the matter is that the phenomenon of industrial melanism was nowhere near as important to the careers of Kettlewell's associates as Hooper suggests. One indication of this is the very limited amount of space devoted to discussing Ford and Sheppard's work on industrial melanism in biographical memoirs written for Fellows of the Royal Society (C. Clarke, 1977; B. Clarke, 1995). Ford includes it only as an afterthought among his recollections on the work he and his colleagues did, and because of its importance to the evolutionary synthesis (Mayr and Provine, 1980: 334-42). Indeed, he does not even mention it on an extended list of his major accomplishments in genetics, written late in his career. ${ }^{11}$

The importance of industrial melanism for Kettlewell's career. Kettlewell's specific motive to commit fraud, according to Hooper, lay in a host of insecurities surrounding his mid-life career shift from an established general practitioner to a tenuous research appointment at Oxford University (p. 90) and a desire to please his boss, Ford (pp. 295-6). As noted above, she emphasizes he was an "amateur," and draws great attention to the fact that Kettlewell did not have "an advanced degree" (p. 123), disparaging his previous medical training (M.A., M.B., B.Chir. 1933; M.R.C.S., L.R.C.P. 1934). This characterization loses sight of the fact that much of the funding Ford and his associates received from the Nuffield Foundation stemmed from their ability to spell out the connection of their work to issues of medical importance and how very much strengthened that case was when a doctor by training became affiliated with Ford's unit. ${ }^{12}$ While the fact that Kettlewell did not have a $\mathrm{Ph} . \mathrm{D}$. probably did undermine his stature among junior colleagues later in his career (he received his D.Sc. in 1975), it is important to note that Ford never received a doctoral degree ${ }^{13}$ moreover, the necessity of having one at Oxford is a relatively recent phenomenon (Morrell, 1997). Hooper also depicts Kettlewell as an outsider (pp. 130-1) and a man without a college (p. 185), ignoring his affiliation with Brasenose College (a sister college of Caius College at Cambridge, where Kettlewell trained as an undergraduate), which was established shortly after his appointment at Oxford. ${ }^{14}$

This being said, there is no doubt that Kettlewell probably felt insecure when he first became affiliated with Ford's sub-department, surrounded by such luminaries as E.B. Ford, Philip Sheppard, and A.J. Cain, each of whom set high standards for themselves and expected the same in others. Indeed, when one considers how Kettlewell parleyed his investigations on the phenomenon of industrial melanism into a career and their subsequent reception by his colleagues, scientists in general and the lay public, his motive for committing fraud seems transparent. The problem with this line of reasoning is that, at the time of his investigations, none of these factors would have been obvious to Kettlewell. It is 
easy, in view of their subsequent fame, to forget the fact that in the early 1950s Kettlewell pursued multiple lines of inquiry, some of which had nothing to do with industrial melanism. A list of work that was begun in September 1951 prominently features five lines of work he was doing that were related to industrial melanism, but it also mentions that he was conducting breeding experiments on a stock of Pieris napi as well as using radioactive isotopes to track lepidopteran and locust populations. ${ }^{15}$

Although she does not discuss it at length, Kettlewell's radioactive tracer work is particularly revealing with respect to Hooper's thesis. His initial work in the early 1950s documented that radioactive isotopes had enormous potential when it came to tracking populations of Lepidoptera (Kettlewell, 1952). This attracted the attention of Boris P. Uvarov, Director of the Anti-Locust Research Centre based at the British Museum (Natural History), who subsequently provided funding for Kettlewell to pursue a similar line of research in order to assess the potential of the method for tracking locust migrations in South Africa. ${ }^{16}$ This research attracted media attention (Walling, 1953), ${ }^{17}$ and it is hardly a stretch to conclude further that if it had been successful, it would have led to additional funding. Indeed, in early February 1954, during his negotiations with Ford about whether to return to Oxford, Kettlewell suggested he would turn over his work on industrial melanism to Ford in favor of continuing his work on locusts. ${ }^{18}$ As he could not return to England for tax reasons, Kettlewell was financially dependent upon the Anti-Locust Research Centre. He had every reason to believe that, as a pioneer of this new technique, his future might lie with radioactive isotope markers, rather than with industrial melanism. These are all the sorts of motives Hooper implies should have led Kettlewell to commit fraud during his radioactive tracer work. Yet, he did not; in fact, he went out of his way when publishing his results on the locust work to draw attention to the fact that the use of radioactive isotopes had "no advantage" over Ford's previous technique of using cellulose paint (Kettlewell, 1955a).

In any event, establishing that Kettlewell had a motive is not sufficient to establish that he committed fraud, any more than establishing motive-in the absence of foul play (let alone a body) — would be sufficient to charge someone with murder. Of course, scientists want their investigations to succeed, but this consideration in and of itself most certainly does not imply that every time a scientist is successful, the results of his/her investigations should be immediately suspect.

\section{Was fraud even committed?}

Members of the scientific community have long acknowledged problems associated with the assumptions and conduct of Kettlewell's investigations (Majerus, 1998). Yet, among the many scientists who have worked on this phenomenon over the past 50 years, neither Kettlewell's colleagues, nor his severest critics, nor researchers since have ever alleged that he committed fraud; nor has any historian of biology. In this light, it is quite surprising how little space Hooper devotes to establishing that fraud has indeed been committed. Her argument rests primarily on five lines of evidence, which are themselves characteristic of the reasoning that runs through her account.

First, she draws attention to the fact that Kettlewell's field notes have never been found, and she quotes Dr. Bruce Grant who commented that this is "very peculiar" (p. 296). After drawing attention to the fact that Ford regularly destroyed his correspondence and research material and that his decision to do so might have been motivated out of a desire to cover up fraudulent results (pp. 234-5), Hooper clearly implies that a similar line of reasoning may have led Kettlewell to destroy his papers as well. Even a brief visit to the Kettlewell archive will convince one that Kettlewell did not regularly destroy his correspondence; virtually 
every bit of his professional correspondence, including several letters that are less than flattering, have been preserved. While it is true that his field notes have never been found, there is no reason to assume that Kettlewell himself was responsible for their disappearance. Dr. David Lees, who worked with Kettlewell, draws attention to the fact that field notes and breeding results were often stored in the department; in other words, if they were destroyed, Kettlewell may not even have been aware of it at the time. More to the point, if they were available, precisely what could possibly be in them that would indicate they were indeed fraudulent? Philip Sheppard's field notes from similar experiments are available. ${ }^{19}$ Assuming Kettlewell kept track of his results in a similar fashion, it is hard to see how, short of evidence that low recapture rate numbers had been scratched out in favor of higher ones, this would support Hooper's contention that they were fraudulent at all. Or, conversely, if he had created a nice fraudulent field notebook, why would he have destroyed it?

Second, Hooper draws great attention to what she perceives as problems surrounding the conduct of his investigations as reported in Kettlewell (1955b). Hooper interprets the several false starts Kettlewell reports as indicative of his willingness to tinker with his investigation until he got the results he wanted. ${ }^{20}$ This interpretation rests, as will be shown below, on a fundamental misunderstanding about how fieldwork in biology is carried out. This concern aside, if Kettlewell did indeed "fudge" his data, why did he not suppress additional details that likewise might have called his investigation into question? Hooper suggests he simply was not savvy enough to realize the importance of doing this:

As an amateur, Bernard did not always master the idiom of science, and he frequently betrayed himself in his papers where others would have known how to cover their tracks. In writing up the aviary experiment, he had failed to conceal the false starts he made before hitting on the experimental design that worked. (p. 159)

As Hooper herself acknowledges, Sheppard and Ford both carefully examined and revised Kettlewell's paper prior to its publication (p. 126), and thus on this line of reasoning two scientists who are implied to be co-conspirators were equally naive. The candid nature with which Kettlewell reports precisely what he did, the problems he encountered, and how he attempted to resolve them all suggest that the report was brutally honest, even when the details reflected negatively on him.

Hooper's third and most specific line of evidence is what she interprets as a discrepancy in the recapture rates Kettlewell reported in his 1955 and 1956 papers (p. 116). She draws great attention to the fact that recapture frequencies dramatically rose in the middle of the experiments (p. 254). With the assistance of Theodore Sargent, a US researcher on industrial melanism whom Hooper describes as Kettlewell's "nemesis" (p. 313), and Donald Kroodsma, a biologist who has not done research on the phenomenon, Hooper concluded that the discrepancy was real. ${ }^{21}$ After rejecting one alternative hypothesis suggested by Michael Majerus - namely that unfavorable weather conditions might account for the discrepancy—she concludes that Kettlewell "fudged" his data to placate his "boss," Ford.

Hooper bases this interpretation on the fact that Kettlewell had the opportunity to hide or alter data he did not like. Discounting multiple uses of the word "we" in his paper as simply a scientific convention (Kettlewell, 1955b: 325, 333, 335-8), not to mention the phrase "I and two others" that is used to describe the collection of moths from assembling traps (Kettlewell, 1955b: 331), she suggests only his wife Hazel was present. ${ }^{22}$ In fact, there are, numerous references among Kettlewell's correspondence as well as his published work that document he was accompanied "by others." 23 As noted in his 1955 paper as well as in his correspondence, ${ }^{24}$ Kettlewell sought out and received independent confirmation of his interpretation of scoring experiments by Dr. R.A. Hinde and Dr. H.B. Cott during his 
preliminary experiments at the Ornithological Field Station in Madingley, Cambridge. And in a thank you letter to the Cadburys, his hosts during the original experiments, shortly after his 1953 experiment, he writes:

We were very sorry to miss you on the road yesterday; in fact, we parked the caravan ready for you a few miles short of Warwick and had drinks waiting for you. Then we realized that you might have come back from Henley via Stratford on Avon. We were so assured of seeing you that I did not leave you a note to say thank you so much for all you did for us and all the help you gave to make it a successful week . . . [He then summarizes results of his experiments for the benefit of Christopher, inadvertently retaining keys to the chalet.] What a time I had shutting down camp. I must have made quite a dozen journeys to the bottom of the valley to collect equipment but we arrived here on time (3.30) and had everything thoroughly under control by 6 o'clock ... (KA, Box 12, Cadbury, J.C., letter to Honor and Christopher Cadbury (6 July 1953))

The letter specifically implies that the Cadburys did not assist in taking down the equipment, and thus the "help" referred to was either in the original setup or in the conduct of the experiment. $^{25}$

Hooper also draws great attention to the fact that the recapture rates rose in the predicted manner they should have on 1 July 1953, the day Ford wrote Kettlewell the following letter:

Dear Bernard, I am glad to hear you have so satisfactory a place in which to work. It is disappointing that the recoveries are not better and curious that you are getting $10 \%$ of typical betularia. However, I do not doubt that the results will be very worthwhile . . (KA Box 17, E.B. Ford, letter from Ford (1 July 1953))

Hooper interprets the letter as follows:

We don't know exactly what state Bernard was in, but we can deduce something of it from a letter dated 1 July from Henry, who wrote: "It is disappointing that the recoveries are not better ... However, I do not doubt that the results will be very well worth while ..." The message sounds benign enough, but knowing Henry, Bernard might have decoded it to mean: "Now I do hope you will get hold of yourself and deliver up some decent numbers." At the best of times, Bernard was an excitable man, with moods prone to roller coaster from giddy highs to Stygian lows. He now felt that his fate as a scientist was hanging on this experiment. The stresses of lumbago and the difficult fieldwork, not to mention the pervasive pressures of Oxford, would not have brightened his outlook. (pp. 114-15)

There are at least three problems associated with Hooper's interpretation. First, there is no reason to assume that Ford's letter should not be taken at face value as simply intended to console a relatively new researcher during a difficult field investigation (Coyne, 2002: 19). Second, the timing does not support Hooper's interpretation: she alleges that the rise in recapture rates was a result of Kettlewell receiving a letter on the same day Ford wrote it. Unless one presumes Kettlewell threw out data he collected on 1 July and created new data in response to Ford's message after receiving the letter, this seems completely implausible. Third, it is possible to gather insights into "Bernard's state" by examining letters he wrote on the day in question (30 June). In three different letters he wrote to Leslie Farrer-Brown, B.P. Uvarov and Col. Bowater on 30 June he describes the results of his experiments as "most interesting" or "very interesting." 26 These are hardly the descriptions one would expect of someone so discouraged by his results that he would consider committing fraud. 
Beyond all this, the "discrepancy" Hooper draws attention to, namely the fact that the recapture rate rose from 14 percent on 29 June to 22 percent on 1 July, does not constitute a dramatic rise in recapture rates by any stretch of the imagination. Anyone familiar with fieldwork knows that field data are highly variable, and that the sort of variation one finds in the results reported in Kettlewell's papers is entirely normal. More to the point, this variation is entirely explicable when one considers that the efficiency of the assembling traps changes with the age of the virgin females being used, and that the numbers of moths Kettlewell marked and released into the wild increased substantially as fresh moths emerged from his breeding stocks. ${ }^{27}$

As a fourth line of argument, Hooper draws attention to how nicely Kettlewell's results fitted with his prediction (p. 256). She points out that one reason why R.A. Fisher came to doubt the results of Gregor Mendel's pea plant breeding experiments is that they fit too closely with the predictions of Mendel's theory (pp. 235-6). In other words, all other things being equal, if the match between theory and experiment is too neat, this is reason to suspect that the results have been doctored to make them fit. The manifest problem with this line of reasoning when it comes to Kettlewell's original Birmingham experiment is that the available evidence strongly suggests that he expected the recapture rates to be much lower than they actually turned out to be. In a letter to J.B.S. Haldane, he writes:

We have found your paper on the selective advantage of betularia ab. doubledayaria in the Transactions as you said we should, but why in the index of the Proceedings for this year it says "Trans: see Proceedings" I know not. You calculated a 30\% selective advantage on the original Manchester melanic. Both in the Isle of Wight and Ireland odd specimens of doubledayaria have turned up this year for the first time and it should be interesting to see if the rate of spread follows the original example. Your figure of $30 \%$ selective advantage has given me great encouragement as it should be possible to show this with much fewer individuals in "mark and release" experiments on both phenotypes than I had thought would be necessary. (KA, Box 18, Haldane, J.B.S., letter to Haldane (16 September 1952))

In the days and months since Kettlewell wrote this letter, he also repeatedly drew attention to the fact that he was concerned that the numbers of moths he planned to use would be insufficient, because he strongly suspected that for a number of practical reasons (e.g. migration from the test site) his recapture rates would be quite low. ${ }^{28}$ If Kettlewell were going to commit fraud, surely he would have created figures that were more in accord with his antecedent expectations. Indeed, it would have been particularly prudent on his part to have invented figures that were lower than Haldane's prediction, both to avoid the suggestion he had committed fraud and against the possibility someone might check up on him by repeating the experiment. But, as we all know, the recapture rate Kettlewell recorded as a result of his 1953 experiment was a selective advantage of 50 percent, not 30 percent. Likewise, when it came to his later 1955 experiment in the Dorset wood, he expected the results to be a mirror image. Yet, in fact, the recapture rates were significantly higher and the advantage for the pale form in this habitat was higher than that for the black form in the polluted wood.

A final consideration Hooper raises against Kettlewell (and research in field settings more in general) is the fact that he "tinkered" with the results of his investigations until he got the results he wanted, which she regards as fraudulent. ${ }^{29}$ One can certainly agree with Hooper that if Kettlewell haphazardly altered variables until he got the results he wanted and 
disregarded the results of previous unsuccessful trials, this would be an example of fraud. But this is an altogether unfair characterization of Kettlewell's conduct, and completely ignores several logistic problems that arise in the context of fieldwork, particularly when one is conducting an investigation for the first time. ${ }^{30}$

It is all too easy to forget that, in 1953, Kettlewell had never conducted an investigation like this before, and as such, like any new researcher, encountered problems that he had not anticipated, such as how precisely to release the moths in a manner that would encourage them to take up their natural resting positions. This is precisely the sort of detail that one learns by trial and error. Kettlewell also encountered problems that were a logical consequence of a tension between minimizing the artificiality of the testing conditions and ensuring that the results of his investigation would be measurable within the limited amount of time available. For example, Kettlewell knew from the start that the density of moths he was using would be in excess of what one encounters in nature, but he also knew that below a certain threshold, the results would not be statistically significant (Rudge, 1999). The "tinkering" Kettlewell did in the field was not haphazard. He had every reason to believe that his failure to obtain the predicted result was an artifact of his procedures, a consequence of unintended sources of error. The changes he introduced were not motivated simply by a desire to get the predicted result - each was justified as the elimination of potential sources of error. This is not a fraudulent practice; the systematic elimination of such sources of error by scientists is one important strategy by which scientists in any context ensure their results are valid (Rudge, 1998). And, in fact, Kettlewell did not fail to report his false starts in the two papers in question (Kettlewell, 1955b, 1956) — both papers are remarkably candid in discussing the problems he encountered in the field and how he overcame them.

Related to her worry about the legitimacy of Kettlewell's tinkering, Hooper openly questions whether it is legitimate for evolutionary biologists to ignore what she regards as potentially falsifying examples, by resorting to what she regards as a series of ad hoc claims intended to preserve the standard account of industrial melanism at any cost (pp. 155, 292-3). This criticism completely loses sight of the fact that the standard explanation of the phenomenon of industrial melanism we associate with Kettlewell is an idealization. Scientists in all contexts explain departures from idealized models with reference to relevant contingent details. This is not a matter of a scientist being dogmatic in the face of overwhelming evidence to the contrary, any more than when a physicist accounts for deviations from Newton's laws of motion with reference to the effects of friction. The fact that there are no frictionless surfaces does not lead physicists to abandon Newton's laws as useful approximations.

This consideration is particularly important in the context of historical sciences such as evolutionary biology. Biological phenomena are historical entities and, consequently, the applicability of a particular model for any specific population depends upon a host of contingent circumstances. ${ }^{31}$ This does not imply that "anything goes" in biology—scientists must establish that reference to the details in question is indeed warranted. Thus, in the case of Ford and Kettlewell's explanation of the phenomenon of industrial melanism, scientists explain deviations from what is expected based on the model with reference to the resting site of moths, the genetics underlying melanism, the amount of migration that occurs, the amount and type of predation, meteorological conditions, and the presence, type and amount of pollution. When we recognize that even in the case of a single species, such as the peppered moth, the circumstances of each component population are unique, we should not be surprised that the precise applicability of the model and what details must be referred to in order to account for the dynamics of that population are subject to change. ${ }^{32}$ 


\section{Summary and conclusions}

Did Kettlewell commit fraud? While we can never know for certain, the foregoing demonstrates that Hooper (2002) does not provide one shred of evidence to support this serious allegation. In retrospect, the multiple historiographic problems of Hooper's approach to this episode seem obvious. She decided in advance that she wanted to tell an entomological "whodunnit" story regardless of whether fraud had actually been committed (Coyne, 2002). Her research consisted of a careful search through archives and published documents to exhaustively list questionable assumptions, methodological errors and interpretive problems associated with Kettlewell's investigations, in order to make them appear suspect (pp. xviii-xix, 216-18, 259-71). The fact that the authors of these critical publications have their own agenda, or even recognition that to get published, a premium is placed upon how new results represent an advance on previous work (which tends to emphasize a few points of difference, while minimizing broad areas of agreement) seems never to have occurred to her. She steadfastly refused to consider the possibility that these discrepancies might be innocent, explicable by reasons she ignores, or perhaps indicative of an active area of science where knowledge is tentative. In lieu of any direct evidence, she draws attention to how the possibility that Kettlewell committed fraud, and that his colleagues at Oxford may have engaged in a conspiracy to hide the truth, might account for these discrepancies. She repeatedly cites quotations from letters and published documents that, out of context, might be interpreted as supporting the conspiracy theory. In the multiple instances where the evidence directly contradicts the conspiracy theory, she either ignores the evidence, or suggests the author was insincere and had ulterior motives for lying. Beyond all this, as noted above, the interpretive framework she provides rests on several fundamental misunderstandings about the nature of science.

This being said, there are several general conclusions about how science should be depicted to the public that follow from this analysis.

First, textbook accounts and popularizations, by virtue of space constraints and their intended audiences, cannot be expected to present the full breadth and variation of science in all its gory detail. Textbook accounts written for children-by their nature-suggest that scientific conclusions are known with much more certitude than is indeed the case. Thus, it should not come as a surprise that textbook accounts differ from journal articles written for professional scientists on subjects of active research. Conspiracy theories are entirely unnecessary to account for these discrepancies.

Second, investigations by past scientists must be judged with reference to the prevailing standards of the time they were conducted, in their own social and cultural contexts. It is trivially true that after a period of 50 years, a pioneering investigation like Kettlewell's will fall short of contemporary standards. No scientist should be put in the position of defending him/herself for not being aware of future standards, nor should they be criticized for making what at the time seemed reasonable assumptions, which subsequent work has shown to be partly or completely false. Being wrong does not make one a bad scientist.

Third, continuing to believe in a theory despite multiple outstanding problems does not imply that a scientist is being dogmatic or irrational. These problems always have to be balanced against the evidence in favor of the theory, and, in particular, whether there is a more plausible alternative available. Outstanding problems and ongoing attempts to refine a theory to account for these discrepancies, far from being signs of dogmatism, are instead indicative of an active area of research.

Fourth and finally, none of these conclusions is specific to the Kettlewell episode. There is a story behind every fact in science. Our record of past investigations is always 
incomplete, both because some details were never recorded and because sometimes records are lost. In the presence of numerous gaps, it is too easy to attribute discrepancies to fraud and conspiracy. No episode in the history of science would survive the sort of analysis Hooper applies to Kettlewell's research. This is not because the history of science is fraught with fraud, but rather because Hooper's subjective analysis places the burden of proof on the scientist to prove he/she was innocent. As has been shown above, with a sufficiently creative interpretation of evidence, almost anything that might be used to defend Kettlewell against these baseless charges can be dismissed as insincere.

\section{Acknowledgements}

Work on this paper was supported in part by internal funding by Texas A\&M University's Office of International Grants (1997) and Western Michigan University's Office of the Vice President for Research (2003) that supported two month-long trips to the Kettlewell and Ford Archives currently at the Bodleian Library, Oxford. Adrian Hale and Tom Kiely, Wolfson College, Oxford assisted the author during his first trip; Colin Harris and Oliver House assisted him on the second. The author acknowledges the kind permission of the President and Fellows of Wolfson College, Oxford to quote from material held the Kettlewell Archive. External funding provided by the American Philosophical Society Library supported an additional month-long trip to the Sheppard Archive. The author gratefully acknowledges advice on an earlier draft of this manuscript from the following scientists who have worked on industrial melanism and/or were former colleagues and associates of Bernard Kettlewell: R.J. Berry, E. Classey, L. Cook, B.S. Grant, J.G. Pusey, J.R.G. Turner, R.I. Vane-Wright, D.A. West and E.P. Wiltshire. The author also acknowledges the assistance of I. Musgrave as well as of U. Geer, E. Howe and S. Malcolm at Western Michigan University, all of whom carefully reviewed the manuscript.

\section{Notes}

1 Quotations and page references are from Hooper (2002) unless otherwise indicated. In the text and notes that follow, manuscripts and correspondence from archives are referred to by the following convention: FA (The E.B. Ford Archive, Oxford University), KA (The H.B.D. Kettlewell Archive, Oxford University) and SA (The Philip M. Sheppard Archive, American Philosophical Society Library). Following the name of the archive, the note subsequently identifies the Box, Folder, and Item consulted. Correspondence is between the scientist whose papers have been placed in the archive and the person whose name is used to identify the box/folder, unless otherwise indicated.

2 "Scientists are extremely reluctant to accuse other scientists of 'fudging,' the highest crime in science. .." (Hooper, 2002: 236).

3 Hooper's tacit comparison of her analysis of fraud in the case of Kettlewell's work on the peppered moth with that of Karl Sabbagh's careful examination of charges of fraud surrounding J.W. Heslop-Harrison's botanical work on the Isle of Rhum [Rum] is unintentionally quite revealing. Sabbagh's analysis stems from charges made by contemporary scientists of Heslop-Harrison and follows the trail of evidence that led John Raven to ultimately conclude that many of the plants Heslop-Harrison claimed to have discovered on the Isle of Rhum were introduced either by Heslop-Harrison or by his students. Sabbagh goes out of his way to consider alternative explanations that might account for the discrepancies Raven found. Hooper's analysis does not stem from concerns previously raised by scientists, nor (as discussed below) is her treatment of the evidence she uncovers without apparent bias.

4 Similar passages in other parts of the book referring to Kettlewell's background choice experiments and his investigations of the build-up of dominance also imply that Kettlewell committed fraud (see Hooper, 2002: 255, 296).

5 Cain (1988) disputes that such a school ever existed. However, it is important to recognize that Turner used the appellation "school" to refer to an invisible college, i.e., a group of individuals with a shared set of related scientific problems and methodologies who consulted with one another on a regular basis (Turner, 1988). 
6 For instance, most of the first chapter is devoted to emphasizing how odd and eccentric entomologists, particularly lepidopterists are (as if similar eccentricities are not part of the culture of any group of professionals or hobbyists). While ostensibly used to romanticize bug hunting and the fervor with which amateurs pursue their hobby, the undertext of this chapter is clear, namely establishing that entomologists are very odd peoplesingle-minded individuals who would resort to almost anything to obtain rare specimens and to achieve recognition for their findings. As naturalists, Kettlewell and Ford are objects of suspicion right from the start.

7 KA, Box 14, Cockayne, E.A., letter from Cockayne (28 May 1946). The letter indicates that Cockayne declined the invitation.

8 R.J. Berry disputes Hooper's interpretation of his remark:

I don't know whether I have regrets about describing Kettlewell as one of the worst professional scientists I have known. It is true, but it carries the implication that his work was therefore poor, which is not true. Kettlewell was an exemplar of someone who could translate natural history observations into hard data for scientific analysis. Niko Tinbergen and Miriam Rothschild were others of the same ilk. I regard this as a greater talent than that possessed by many run-of-the-mill academics who argue along drearily rational and predictable tramlines. The fact that Kettlewell was not a paragon of every single intellectual virtue ought not to be allowed to belittle his particular talents and skills, which were great. Linking natural history to mainstream science is much more a British than an American tradition. (R.J. Berry's letter to D.W. Rudge, 29 December 2003)

9 "Bernard was not capable of acting in any way but a gentleman. He made mistakes (don't we all!) but he would agree with me [that] 'The man who never made mistakes never made anything!' . . I never knew him to shrink from confessing his errors and he welcomed criticism as a contribution to further thought and work" (message from Eric Classey to D.W. Rudge, 24 January 2004). E.P. Wiltshire, another associate of Kettlewell agrees: "Whatever happened to Bernard $\mathrm{K}$ at the end of his life, he certainly was admired in the fifties and no one then would [have] believe[d] he could be a 'fraud' or a 'fiddler'" (E.P. Wiltshire's letter to D.W. Rudge, 23 December 2003).

10 While the work of two of Kettlewell's colleagues, A.J. Cain and Philip Sheppard, on snail shell banding patterns in Cepaea nemoralis did figure prominently in debates about drift, it was because their study was seen as a convincing refutation of Maxime Lamotte's previous study that suggested that snail banding patterns might be due to drift (Clarke, 2003).

11 FA, Box A, Folder 10, "The Experimental Work of E. B. Ford"-his answers to a suggested final examination inviting students to assess his contribution to genetics.

12 The work of Cyril Clarke (also a medical doctor by training) and Philip Sheppard likewise attracted funding by establishing the medical significance of their work.

13 Charles Elton, another luminary of ecology and a contemporary of Kettlewell at Oxford also had no advanced degree.

14 KA, Box 1, Professional Career, Brasenose College. Papers in this file suggest he had an informal association with the college as early as 30 May 1955.

15 KA, Box 1, Nuffield Foundation, Report of work Kettlewell commenced in September 1951.

16 KA, Box 27, Uvarov, B.P., letter from Uvarov (6 October 1952).

17 The author gratefully acknowledges Ms. Louise Jarvis' assistance in locating this article.

18

I have just received your letter of February 3rd, in which you are good enough to offer me a post in your Genetic Laboratories as a Research Worker, commencing May 1st 1954 and terminating September 1956. It is with the greatest regret (how great I am sure you will realise) that I shall be unable to accept it. The sole reason for this is, of course, that I am advised by my Chartered Accountants that if I visit England again in the near future, I may be taxed in retrospect for previous years . . . It is all the more annoying to me that this offer comes at a time when, after five months of work out here applying the technique of radio-active labelling of Locusts - (the same technique I was developing at Oxford with Panaxia dominula - it is becoming increasingly obvious that it is virtually impossible to conduct this work so far away from the source of origin of the isotopes. I shall be prepared to hand over my Laboratory notes and details of all field work up to date on the following: Air pollution figures for 1952-53 . . Figures for viability differences for larvae of Biston betularia . . . Gene frequency figures for Biston betularia . . . (KA, Box 7, Travel £4 South Africa letter to E.B. Ford, dated 13 February 1954)

19 SA, Series III Box 1: [Biston betularia], notes re. recapture figures from 1959-64.

In the aviary Bernard had fiddled with his experiment, laying out, after two unpromising starts, a smorgasbord of bugs to get the results he wanted. It would have been natural for him to try to fix what wasn't working, just as he would have tinkered with a sputtering generator or changed the position of a cage in which two moths refused to mate. Is it possible that he made modifications to his experimental 
design in Beacon Wood? Working solo, Bernard made all the decisions about how many moths to place on each tree trunk, where to place the carbonaria and typicals, how far apart to space the moths. He alone rated the crypsis of each moth against its background and identified his catches by phenotype. (p. 118, see also pp. 112-13)

21 As one scientist who reviewed Hooper's book has pointed out, there are multiple reasons that might account for this apparent discrepancy, not one of which supports her contention that fraud has occurred (Coyne, 2002: 19). It is particularly significant that neither Kroodsma nor Sargent is identified as agreeing with Hooper's interpretation that this discrepancy constitutes fraud. In fact, Sargent is quoted as specifically denying Hooper's interpretation (p. 255).

Another mystery concerns who was with Bernard in the woods. He uses the pronoun "we" in his papers, but this may have been just a scientific convention, because otherwise, in his letter and reminiscences, there is no trace of anyone else - except Hazel . . . [who] "observed a bird fly out of the bracken, snatch a betularia, and return it to the ground, the whole thing being over in a flash." No one had yet seen a bird in the wild eating a peppered moth off a tree trunk. Without this observation, any number of other things could have been happening to the moths, including being eaten by something else. Thus, this hedge sparrow was heaven-sent, and Bernard reported that he and Hazel were able to "watch this bird regularly at work and to score the order in which it took its phenotypes." (p. 118)

23 See KA, Box 8, Allan, P.B.M., letter to Allan (16 March 1955); KA, Box 15, Demuth, R.P., letter to Demuth (21 March 1955).

24 For example, KA, Box 2, Research \& Equipment £2, letter and attachment to Dr. Hinde (8 August 1953).

25 A letter written much later also strongly suggests their son James assisted Kettlewell in the conduct of his 1955 investigations, prior to his doctoral work with Kettlewell:

Having just been given a grant from the D.S.I.R. for an assistant for three years, I am wondering whether he [James Cadbury] would be suitable . . . I met James Cadbury a few years ago and he actually helped me for a short time with mark-release experiments I was doing, and as I am looking for someone who is more of a "naturalist" than a first class Honours, possibly overspecialized, Biologist, I wondered if he would do. (KA, Box 12, Cadbury, C.J., letter to Sir James Grey (Department of Zoology, Cambridge) (9 May 1959))

26 KA, Box 10, Bowater, Col. W., letter to Bowater (30 June 1953); KA, Box 27, Uvarov, B.P., letter to Uvarov (30 June 1953); KA, Box 1, Nuffield Foundation letter to Farrer-Brown (30 June 1953).

27 The author thanks Dr. Ian Musgrave and Dr. Bruce Grant for their insights on the causes of variability of field data. See also Young and Musgrave (2005).

28

. . My original plan was to do my release experiments somewhere in Devon or Cornwall. You may realize that betularia is not an ideal insect for release experiments because in the first place one loses $50 \%$ (or thereabouts) because practically none of the females come to light and secondly because the males obviously fly from big distances. It is therefore essential to me to find a releasing place giving optimum conditions for return, hence my thought of a circumscribed wood in Devon or Cornwall ... (KA, Box 23, Philpott, V.W., letter to Philpott, 14 May 1953)

and ". . . I have had a most interesting time in the Midlands doing a population study of betularia with marked releases and I think I can say it has been very successful, as strangely I got large numbers back, which is contrary to what I have been told would happen . .." (KA, Box 21, Lees, F.H., letter to Lees, 6 July 1953).

29 See note 20 above. Similar comments are made regarding his mark-recapture experiments on pp. 134-6, 254-5.

30 "Apparently she [Hooper] does not recognize that it is reasonable to discover the conditions that favour the phenomenon you want to study" (Clarke, 2003).

31 This is analogous to how researchers explain other historical events, such as individual plane crashes. A general model of what causes plane crashes may lead investigators to consider the possibility that the crash is due to a design flaw or to pilot error. Evidence that rules out one of these factors does not constitute evidence against the model as a whole.

32 Hooper's concern about the standard account being immune to falsification also ignores the fact that, in Kettlewell's famous predation experiments, there was a null hypothesis at stake that was indeed falsified, namely the hypothesis that the recapture rates would be the same (Rudge, 2001). 


\section{References}

Beatty, J. (1995) "The Evolutionary Contingency Thesis," in G. Wolters and J.G. Lennox (eds) Concepts, Theories, and Rationality in the Biological Sciences: The Second Pittsburgh-Konstanz Colloquium in the Philosophy of Science, pp. 45-81. Pittsburgh, PA: Universitätsverlag Konstanz and Pittsburgh University Press.

Berry, R.J. (1990) "Industrial Melanism and Peppered Moths (Biston betularia (L))," Biological Journal of the Linnean Society 39: 301-22.

Bowler, P.J. (2003) Evolution: History of an Idea, 3rd edition. Berkeley, CA: University of California Press.

Cain, A.J. (1988) “A Criticism of J.R.G. Turner's article 'Fisher's Evolutionary Faith and the Challenge of Mimicry,", in P.H. Harvey and L. Partridge (eds) Oxford Surveys in Evolutionary Biology, Vol. 5, pp. $246-8$. Oxford: Oxford University Press.

Clarke, B.C. (1995) "Edmund Brisco Ford,” Biographical Memoirs of Fellows of the Royal Society 41: 147-68.

Clarke, B.C. (2003) "The Art of Innuendo," Heredity 90: 279-80.

Clarke, C.A. (1977) "Philip MacDonald Sheppard," Biographical Memoirs of Fellows of the Royal Society 23: 465-500.

Cook, L. (2000) "Changing Views on Melanic Moths,” Biological Journal of the Linnean Society 69: 431-41.

Cook, L. (2003) "The Rise and Fall of the Carbonaria Form of the Peppered Moth," The Quarterly Review of Biology 78; 399-417.

Coyne, J.A. (2002) "Evolution under Pressure: A Look at the Controversy about Industrial Melanism in the Peppered Moth," Nature 418: 19-20.

Dobzhansky, Th. (1951) Genetics and the Origin of Species. New York: Columbia University Press.

Ford, E.B. (1975) Ecological Genetics, 4th edition. New York: John Wiley \& Sons.

Ford, E.B. (1979) "H.B.D. Kettlewell," Nature 281: 166.

Gould, S.J. (1983) "The Hardening of the Evolutionary Synthesis," in M. Grene (ed.) Dimensions of Darwinism, pp. 71-93. Cambridge: Cambridge University Press.

Grant, B.S. (1999) "Fine Tuning the Peppered Moth Paradigm," Evolution 53: 980-4.

Grant, B.S., Owen, D.F. and Clarke, C.A. (1996) "Parallel Rise and Fall of Melanic Peppered Moths in America and Britain," Journal of Heredity 87: 351-7.

Haldane, J.B.S. (1924) "A Mathematical Theory of Natural and Artificial Selection," Transactions of the Cambridge Philosophical Society 23: 19-41.

Heslop-Harrison, J.W. (1927) “The Induction of Melanism in the Lepidoptera, and its Evolutionary Significance," Nature 119: 127-9.

Hooper, J. (2002) Of Moths and Men: An Evolutionary Tale. New York: W.W. Norton \& Company.

Kettlewell, H.B.D. (1952) "Use of Radioactive Tracer in the Study of Insect Populations (Lepidoptera)," Nature 170: 584-5.

Kettlewell, H.B.D. (1955a) "Labelling Locusts with Radioactive Isotopes," Nature 175: 821-2.

Kettlewell, H.B.D. (1955b) "Selection Experiments on Industrial Melanism in the Lepidoptera," Heredity 9: 323-42.

Kettlewell, H.B.D. (1956) "Further Selection Experiments on Industrial Melanism in the Lepidoptera," Heredity 10: 287-301.

Kettlewell, H.B.D. (1973) The Evolution of Melanism: The Study of a Recurring Necessity. Oxford: Clarendon Press.

Kitcher, P. (1985) "Darwin's Achievement," in M. Rescuer (ed.) Reason and Rationality in Natural Science, pp. 127-89. Lanham, MD: University Press of America.

Majerus, M.E.N. (1998) Melanism: Evolution in Action. Oxford: Oxford University Press.

Martin, B. (1992) "Scientific Fraud and the Power Structure of Science," Prometheus 10: 83-98.

Mayr, E. and Provine, W. (1980) The Evolutionary Synthesis: Perspectives on the Unification of Biology. Cambridge, MA: Harvard University Press.

Morrell, J. (1997) Science at Oxford, 1914-1939: Transforming an Arts University. Oxford: Clarendon Press.

Provine, W. (1986) Sewall Wright and Evolutionary Biology. Chicago: University of Chicago Press.

Rudge, D.W. (1998) “A Bayesian Analysis of Strategies in Evolutionary Biology," Perspectives on Science 6: $341-60$

Rudge, D.W. (1999) "Taking the Peppered Moth with a Grain of Salt," Biology and Philosophy 14: 9-37.

Rudge, D.W. (2000) "Does Being Wrong Make Kettlewell Wrong for Science Teaching?," Journal of Biological Education 35: 5-11.

Rudge, D.W. (2001) "Kettlewell from an Error Statistician's Point of View," Perspectives on Science 9: 59-77.

Rudge, D.W. (2002) "Cryptic Designs on the Peppered Moth," International Journal of Tropical Biology and Conservation 50: 1-7. 
Rudge, D.W. (2003) “The Role of Photographs and Films in Kettlewell's Popularizations of the Phenomenon of Industrial Melanism," Science and Education 12: 261-87.

Turner, J.R.G. (1985) "Fisher's Evolutionary Faith and the Challenge of Mimicry," in R. Dawkins and M. Ridley (eds) Oxford Surveys in Evolutionary Biology, Vol. 2, pp. 159-95. Oxford: Oxford University Press.

Turner, J.R.G. (1988) "Reply: Men of Fisher's?," in P.H. Harvey and L. Partridge (eds) Oxford Surveys in Evolutionary Biology, Vol. 5, pp. 249-52. Oxford: Oxford University Press.

Walling, Mr. (1953) "Radioactive Insects on the Coast of South Devon. Checking up on them with Geiger Counter. Important Experiments by Scientist," The South Devon Times 21 August, No. 1,703, p. 1.

Wells, J. (2000) Icons of Evolution: Science or Myth? Why Much of What we Teach about Evolution is Wrong. Washington, DC: Regnery Press.

Young, M. and Musgrave, I. (2005) 'Moonshine: Why the peppered moth remains an icon of evolution', Skeptical Inquirer 29: 23-28.

\section{Author}

David Wÿss Rudge is an assistant professor in the Department of Biological Sciences and holds a joint appointment in the Mallinson Institute for Science Education at Western Michigan University. He received his B.S. in zoology from Duke University, an M.S. in biology, and an M.A. and Ph.D. in history and philosophy of science from the University of Pittsburgh. After studying several philosophical questions concerning how experiments and observations are used in evolutionary biology on the basis of several historical episodes, the focus of his research has shifted to a consideration of the potential role of history and philosophy of science for science education. He is currently writing a book on H.B.D. Kettlewell's classic investigations on the phenomenon of industrial melanism, with special attention to how the episode has been portrayed in science textbooks and the popular media. Correspondence: Department of Biological Sciences, Western Michigan University, 3134 Wood Hall, Kalamazoo, MI 49008-5410, USA; email: david.rudge@wmich.edu 